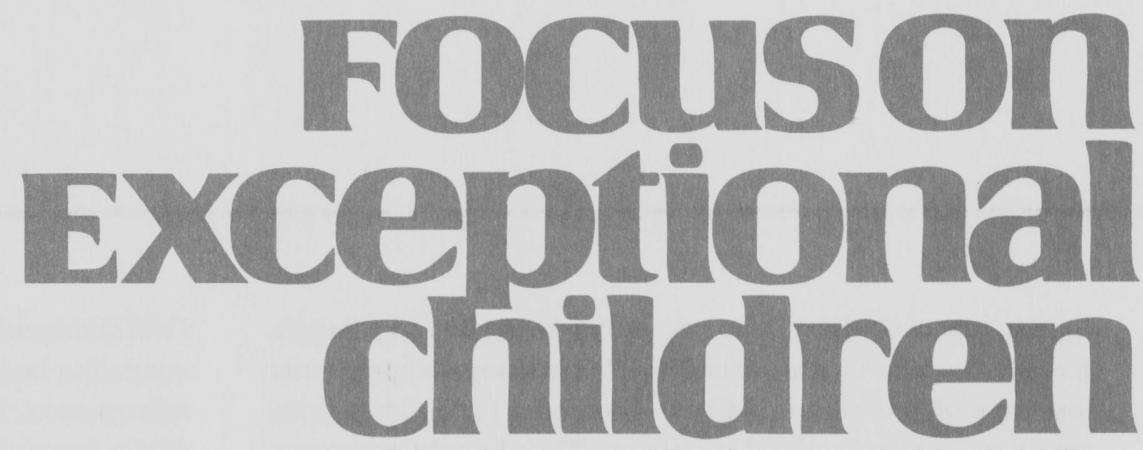

\title{
Constructive Classroom Management
}

\author{
Norin Dollard, Linda Christensen, Karen Colucci, \\ and Betty Epanchin
}

\begin{abstract}
Power is the strength and the ability to see yourself through the eyes of another. It is being able to place a circle of power at your own feet and not take power away from someone else's circle. (Agnes Whistling Elk)
\end{abstract}

Teachers in schools today are challenged on many levels as they try to organize and maintain an orderly, harmonious, and stimulating learning environment. Environmental challenges include interruptions from the loudspeaker, student messengers with a myriad of requests, and children leaving and returning from special programs. More troubling challenges stem from the need to help children cope with emotionally difficult situations: alcohol and drug abuse, physical and sexual abuse, separation and divorce of parents, moving, pregnancy, and stress at home such as unemployment. Teachers also face challenges when working with colleagues who don't carry through with their responsibilities, colleagues who are abrasive or indifferent to others and colleagues who hold different opinions about professional issues. In addition, challenges come from the many different roles in which teachers must function: member of the child study team, contributor to the school improvement team, coach for an athletic team, advocate for a child in need, and counselor to parents under stress. To complicate matters further, there are few clear cut or "right" ways of addressing these challenges. Like many other fields, education is undergoing some radical changes in philosophy about teaching, learning, and administering schools. Teachers are faced with important and complicated decisions with conflicting and confusing guidelines about how to respond.

Eitzen (1992) believes we are in the midst of "one of the most profound transformations in history, similar in magnitude and consequence to the Industrial Revolution" (p. 586). He said that "several powerful forces are converging to transform the U.S. economy by redesigning and redistributing jobs, exacerbating inequalities, reorganizing cities and regions, and profoundly affecting families and individuals" (p. 586). Based on the assumption that families and individuals are shaped in fundamental ways by their economic situation, he predicts the changing economic picture is certain to have an adverse impact on many families, which in turn will have an impact on our schools.

Norin Dollard is a third-year doctoral student, Karen Colucci is a visiting assistant professor, and Betty Epanchin is a professor at the University of South Florida, Tampa. Linda Christensen is a professor at Montana State University, Billings. 
The impact of these changes is already evident in schools. Knitzer, Steinberg, and Fleisch (1990) investigated programs that were identified originally as good ones for children with emotional and behavioral problems. They found that across the country, and across economic and racial boundaries, the schools they studied were very much alike. The overwhelming majority of classes and school structures within both general and special education settings emphasized control.

It can be argued that these efforts to control are responses to the need to preserve a sense of order or counteractions to the impending sense of lack of control. Contrary to American educational mythology, however, Nichols (1992) noted that highly regimented and controlling environments are counterproductive to learning. She observed that overly controlled environments intimidate students who are able to control themselves and often exacerbate the very behaviors the control techniques are intended to squelch in students who are unable or unwilling to control themselves. Further, these environments decrease teachers' self-esteem, which has been linked to academic progress (Aspy \& Buhler, 1975).

Not only do overcontrolling environments impede student learning, but they also seem to demoralize teachers. Nichols

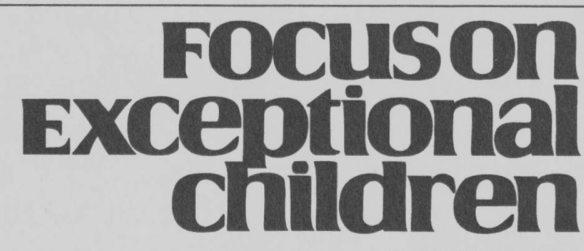

ISSN 0015-511X

FOCUS ON EXCEPTIONAL CHILDREN (USPS 203-360) is published monthly except June, July, and August as a service to teachers, special educators, curriculum specialists, administrators, and those concerned with the special education of exceptional children. This publication is annotated and indexed by the ERIC Clearinghouse on Handicapped and Gifted Children for publication in the monthly Current Index to Journals in Education (CIJE) and the quarterly index, Exceptional Children Education Resources (ECER). The full text of Focus on Exceptional Children is also available in the electronic versions of the Education Index. It is also available in microfilm from Xerox University Microfilms, Ann Arbor, MI. Subscription rates: Individual, \$30 per year; institutions, $\$ 40$ per year. Copyright (C) 1996, Love Publishing Company. All rights reserved. Reproduction in whole or part without written permission is prohibited. Printed in the United States of America. Periodicals postage is paid at Denver, Colorado. POSTMASTER: Send address changes to:

$$
\begin{gathered}
\text { Love Publishing Company } \\
\text { Executive and Editorial Office } \\
\text { P.O. Box } 22353 \\
\text { Denver, Colorado } 80222 \\
\text { Telephone (303) } 757-2579
\end{gathered}
$$

Edward L. Meyen University of Kansas
Glenn A. Vergason Georgia State University
Richard J. Whelan

University of Kansas Medical Center
(1992) noted, "No one went into teaching because he or she wanted to be boring, controlling and miserable" (p. 11). In a related vein, Poplin and her colleagues (Poplin \& Weeres, 1992) found that virtually everyone in the secondary schools they studied was concerned about the disruptions in human relationships throughout their school. Students, teachers, administrators, and allied personnel all felt disconnected from each other. Environments that are impersonal and disjointed do not lend themselves to meaningful dialogue and relationships among teachers, students, administrators, and others. Without productive relationships, learning is disrupted.

\section{THE CHANGING VISION OF SCHOOLING}

One of the critical forces behind the changes in schools is our changing vision of school. Over the years, schools have served different purposes, such as forming a moral citizenry, assimilating and enculturating immigrants, and equalizing social and economic disparity. Schlechty (1990) had suggested that early in our history, schools served to promote the culture and induct the young into the traditions of the culture. As Schlechty (1990) noted, "Citizenship and cultural enlightenment became the basis for the school curriculum" (p. 18), and in the United States, the school curriculum was a repository of white, Anglo-Saxon, Protestant culture. Teachers were judged not only by their proficiency in the classroom but also by their moral competence, and they frequently served as community leaders in moral and intellectual activities.

With the influx of non-English-speaking and non-Protestant people at the turn of the century, the purpose of schooling was expanded and modified. Schools were expected to train students to be productive members of society. In this model, much like a factory, students were the raw material to be molded into future citizens. Standards were set against which all products were compared and teachers were the technocrats. The curriculum functioned as "an assembly line for students: a fast curriculum for fast students, a modified curriculum for the not so fast, and a vocational curriculum for others" (Schlechty, 1990, p. 22).

The third purpose that schools have served, according to Schlechty (1990), is as a hospital:

\begin{abstract}
to redress the pain and suffering imposed on children by the urban industrial society. In this view, injustice and inequity in society place some children at a disadvantage or at risk. It is the school's obligation to ensure that these children receive an even break in life. And education is the great equalizer. (p. 25)
\end{abstract}

In this model, students are viewed as clients to be served, teachers as service-delivery professionals, and the curriculum as a highly individualized prescription. 
In reality, these models rarely exist in pure form, but their purposes have persisted, and none of these approaches has yielded programs that are widely considered successful (Schlechty, 1990). The lack of success in attaining any of the goals may be attributed to traditional culture of American schooling. Authority is transmitted hierarchically. Within the classroom this sets up the teacher as expert and power broker. Within the school, this is exemplified by standardized curricula, testing standards imposed on teachers and, in turn, on students without their consent, let alone input. Within curricula, testing standards imposed on the administrators, teachers, and students further bind their hands and impede individualized attention.

Scientific advances, particularly within psychology, also have had an impact on education (Johanningmeier, 1993). The model the field of education adopted is one in which experts discover knowledge and convey it to practitioners (Skrtic, 1991). From this perspective, students are passive, empty vessels upon whom knowledge is conferred (Kreisberg, 1992). Another way in which science has had an impact on education is through its process of breaking down things into increasingly smaller components to gain insights into phenomena. In education, this has resulted in fragmented curricula in which copious facts are relayed without consideration for their relationship to one another, nor relevance to the learner's circumstances.

The confluence of educational measurement and science also has contributed to more nefarious aspects of educationthe emphasis on differences and deficits. Educational diagnoses and labels placed the locus of responsibility for school failure on the child (Skrtic, 1991). This subtle blaming technique increased feelings of apathy and alienation with an attendant decrease in self-esteem and sense of power and efficacy on the part of students. Feelings of frustration among students with differences lead to students" "turning off," and this phenomenon in turn leads teachers to feel their own frustrations (Kreisberg, 1992).

Combined with the long-established tendency to take power from students, parents, and other disenfranchised groups, these frustrations fuel the need to control environments to counter student behaviors. When this fails, greater (i.e., external) powers are called in the form of school administration, and greater control measures are brought to bear. Student alienation and powerlessness is heightened, behaviors may intensify, and the cycle begins anew. Although the goals of education are laudable, the process chosen to achieve them is one that seemingly is destined for failure.

To counter this self-defeating cycle of control, opposition, punishment, and more control followed by more opposition and alienation, schools have to find ways to reverse the cycle. In his analysis of power relationships within schools and other institutions, Kreisberg (1992) advocated reshaping relation- ships from the historical structures of power (i.e., coercion) over to the shared structure of power with as an essential path to transforming schools. Schlechty (1990) suggested that schools should be redesigned for a different purpose than the ones discussed above. He believes our future well-being depends upon our ability to solve problems, to think creatively, and to work together. Schools should become places that teach students how to learn by engaging in "knowledge-work." Schools should be places that invent knowledge-work for students so they will learn how to learn. In his system, students are both the worker and the customer. As workers, they engage in constructing knowledge, taking information in the curriculum and processing it so it becomes their own information. As customers, they are the objects that schools seek to engage and keep in the institution. In this system, teachers are inventors and leaders, inventing work that will engage students in learning, and leading students to that work.

\section{THE CONSTRUCTIVIST APPROACH}

The concept of schools as places for "knowledge-work" is consistent philosophically with notions about learning as construction of knowledge. Piaget was among the first to articulate this approach. According to Piaget (1986), learning proceeds through assimilation (relating new information to known information) and accommodation (altering one's understandings on the basis of new insights and information). This approach views learning as an active, creative process of construction. Information becomes highly personal and unique. Teachers are more like coaches, creating situations that facilitate learning. The constructive approach is child-centered. Teaching strategies are dictated by children's needs, not by the teacher's beliefs and preferences. Teachers share their control with their students, and students are expected to control themselves.

While considerable attention has been given to constructive teaching strategies, very little attention has been given to managing classrooms that are based on the constructivist philosophy. The purpose of this article is to review classroom management strategies that are consistent with constructivist approaches. The intention is to look at existing technologies within the framework of constructivism or child-centered teaching.

\section{Building Caring Relationships}

One of the most critical components of child-centered classrooms and instructional environments is positive studentteacher relationships. Without positive relationships with students, teachers are limited in the ways they can interact with students and often resort to methods of control within the classroom (Barth, 1986; Knitzer, Steinberg \& Fleisch, 1990). Positive relationships are characterized by trust, respect, and 
understanding. The positive connection formed within a relationship between student and teacher becomes the foundation for all interaction in the classroom. These relationships give important insights into the child's needs and interests.

This concept of viewing the child in a holistic fashion is key to developing child-centered curricula - those that are relevant, interesting, and take advantage of the student's natural curiosities and past experiences. Further, this relationship draws upon, rather than directs, a multiplicity of perspectives. When students and teachers feel included, they feel valued and important. They feel a greater sense of self-efficacy and are more likely to engage in risk-taking to pursue their educational goals. Including diverse voices enriches the perspectives of all group members and thus allows the consensus-building process to emerge. Once trust and respect have been established within the relationship, students are freed from the encumbrances of worrying about their emotional, physical, and academic safety in the classroom (Noddings, 1992; Poplin \& Weeres, 1992; Raffini, 1993). They can take comfort in knowing that even in the worst crisis, the relationship they have with the teacher will remain a constant and will continue to provide a safe environment in which to work through the crisis.

The student-teacher relationship also can be transformative. It can provide a context for personal growth in which students learn to care for themselves as well as others. The model established by the student-teacher relationship can be used to develop new understandings about relationships and personal interactions.

How then can positive student teacher relationships be developed? Many teachers struggle with this very question. They are haunted by admonitions of fellow teachers: "Don't get too emotionally close to the students; you may get hurt and your authority in the classroom will be undermined" or, "If the students view you as a friend or buddy, you will not have their respect."

In the face of these admonitions, teachers may begin to question a child-centered philosophy of teaching and follow their colleagues' advice. Although following colleagues' advice provides a quick solution to the problem of what kind of relationship to form with students, it does not address the underlying assumptions and implications of developing an authoritarian or controlling relationship with students.

We suggest that relinquishing hierarchical power structures (teacher controlling student) will result in a more "manageable" classroom. As students are given more responsibility for their own behavior and learning, teachers are relieved of the burden of playing police officer or jailer. This is an act of trust on the teacher's part, one that engenders trust on the students' part, and one that will help to consolidate a caring and safe relationship within which learning can occur.

Many students have given up on schools as places where their needs are met in valid, caring ways (Goodlad, 1984; Knitzer, Steinberg \& Fleisch, 1990; Kozol, 1991; Noddings,
1991; Poplin \& Weeres, 1992; Raffini, 1993). Students often talk about the lack of genuine relationships between students and teachers and that this affects their achievement in schools negatively (Knitzer, Steinberg \& Fleisch, 1990; Kozol, 1991; Poplin \& Weeres, 1992; Raffini, 1993). These student perceptions point out an important aspect of student-teacher relationships: genuineness. Student-teacher relationships should be genuine in the sense of having meaning to those involved in the relationship. Each relationship is different and is based on the needs and perspectives of those involved. Students within the relationship need to feel that the real issues they face in their lives can be dealt with within the relationship in a genuine rather than a superficial manner.

Noddings (1991) suggested that many students do not know how to form caring relationships with others. It also might be argued that many teachers are uncertain about how to form caring relationships with their students. An important prerequisite for learning to form relationships and caring for others, Noddings further suggested, is being cared for. Therefore, teachers must take the lead in developing relationships with their students. They must demonstrate to the students actively and consistently that they are cared for. For teachers to take such a role, they may need help in learning how during their teacher preparation programs.

In the sections that follow, we present an emerging conceptualization of teaching and learning that allows for a deeper bond between teachers and students, one that can surmount the difficulties besetting all individuals in all classrooms. Techniques that have long been employed in classroom management are reinterpreted in the context of caring relationships consistent with a constructivist perspective.

We are not suggesting that these ideas are new to teachers. Effective teachers have long been able to establish relationships with students that elicit the best from their students and themselves. They create environments that are conducive to learning, comfortable, and safe, all while challenging classroom members to do their best. These classroom management strategies provide a powerful framework for allowing teachers to teach.

\section{Dialog}

To start building caring relationships, teachers have to enter into meaningful dialogue with students to understand students' perspectives and the issues they face in life. Teachers must be willing to enter into this dialogue in an open and honest manner. They must be aware of how their own biases and values color the way they perceive the student. Bruner (1986) referred to this as the "construal of character." He suggested that the way we perceive others greatly impacts the way we interact with them. More important, though, he stated that we have choices over how we construe others. For example, if a student is frustrating to a teacher because of his violent and 
aggressive behavior, the teacher has a choice in how to construe, or look at, the student. The teacher can look at the student as a behavior problem, or the teacher can look at the student as a multifaceted person in which difficulty in controlling anger is just one facet. By taking the second perspective, the holistic perspective, the teacher has opened up new and different ways in which to interact with the student that are not limited by a one dimensional view. Dialogue with the student then becomes multifaceted rather than superficial.

Most important, dialogue is a vehicle for shared understandings and a tool for building trusting relationships in which the student feels safe in expressing his or her perspective. Raffini (1993) contended that "students discover who they are, what they believe, and what behavior is acceptable through honest self-disclosure with others" (p. 23). This requires that teachers be willing and able to be honest and forthright about the lenses through which they view the world, both to themselves and to their students.

Once the student begins to feel safe within the studentteacher relationship, the student and teacher can begin to work through "real-life issues," crises, and frustrations. Dialogue in these situations continues to be open and honest. The outcome of the dialogue is not predetermined or coerced; rather, it is fluid and transformational. Control is put aside, and the focus of the dialogue becomes shared understandings and mutual decision making about issues at hand. This is not to say that teachers must agree with or condone the actions or perceptions of students. Instead, the teacher must understand the road the student is traveling, or their paths will never meet. The shared understandings also serve to strengthen the relationship between the two participants, and an upward positive spiral of understanding, trust, and respect ensues.

Exemplifying the need for shared understandings is the following situation:

\begin{abstract}
Mrs. Vox, a special education teacher of students with mild to moderate disabilities, was helping to prepare her students for lunch. After the students washed their hands, they began gathering at the door. Patrick, the third student to arrive at the doorway area, began talking to April and Michael, who already were standing there. The three students were engrossed in their conversation when Nicholas, who was approaching the doorway area, tripped over his shoelace and, in so doing, shoved Patrick in the back. Patrick immediately turned around and slapped Nicholas across the head. Mrs. Vox looked up just in time to see Patrick's assault on Nicholas.
\end{abstract}

At this point a crossroad existed. This scenario has many possible endings; two will be explored:

Scenario One. Mrs. Vox takes a controlling stance. She sends Patrick to his seat and tells him that, because he cannot interact appropriately with the other students, he will have to eat lunch in the classroom with Mr. Ross, the classroom aide. She further explains to Patrick that he will not be able to participate in the afternoon kickball game, an activity he had been looking forward to all week.

Patrick begins to protest and blames Nicholas for the incident. Mrs. Vox quickly interrupts him and explains that she saw him hit Nicholas, and that was not acceptable. Further, if Patrick continues to protest, the length of time he is isolated from his classmates will be lengthened. Mrs. Vox knows that Patrick has difficulty controlling his anger. She thinks if she does not "nip it in the bud," he might be compelled to persist in it and it also might spread to the rest of the class. She feels justified in her actions and thinks as she walks out the door, "I have the safety of the rest of the class to think about. I can't let actions like that go unpunished."

As the class walks down the hallway, everyone hears Patrick pounding on his desk and screaming, "I'm going to get you, Nicholas!"

Scenario Two. Mrs. Vox operates from within a child-centered philosophy, and she knows the importance of children taking responsibility for their own actions and learning selfcontrol. After witnessing the incident, Mrs. Vox immediately knows that Patrick's self-control has "gone out the window." After asking Patrick to take some time to "cool off," she takes Nicholas aside to make sure he is all right and to get his perception of the event. After hearing that he had tripped and bumped into Patrick accidentally, she asks the class to go to lunch with Mr. Ross. Mrs. Vox then explains to Nicholas that if he wants to talk more about the incident, they can talk after lunch. When the class leaves, Mrs. Vox asks Patrick if he is ready to talk about what happened. Patrick nods his head in affirmation. He feels safe with Mrs. Vox and trusts her to listen to his side of the story.

She begins by saying that she is having a hard time understanding what happened between him and Nicholas and asks Patrick to help her understand the situation. Patrick responds, "He did it on purpose! He shoved me!" Mrs. Vox says, "You sound very angry."

Patrick pauses and then says, "Yeah, that boy and his family make me mad! His older brother is always picking on me and stuff, and Nicholas just sits back and laughs."

"You felt Nicholas was picking on you just like his brother."

"Yeah. I can't let him get away with that! I'm tired of people picking on me. I gotta stand up to them."

Mrs. Vox replies with understanding, "It's hard when older kids pick on you. Sometimes it can make you feel helpless and scared."

"Yeah, but I'm not going to be scared anymore. I'm mad!"

"Do you think you get so mad sometimes that you act without thinking?" 
Patrick replies, "Yeah, I guess. My mom tells me that all the time."

"What usually happens when you act without thinking?'

"I usually get in a fight or get in trouble."

"How does that make you feel?"

"Bad, I guess. I know I shouldn't have hit Nicholas, but I just get so mad!"

Mrs. Vox wants Patrick to know that she understands his situation and wants to help him come up with a way to deal with it. She says, "Anger is a really hard emotion to control. Sometimes it can cloud our judgment of a situation, and we act before we think. Would you like to work together on a plan to help you control your anger?"

Patrick nods in affirmation.

Mrs. Vox continues by asking Patrick if he would like to work out his differences with Nicholas. She points out that they had been such good friends at the beginning of the school year and seemed to have a lot in common. She asks, "Do you remember that volcano project you both worked on?"

Patrick replies, "Yeah! That was fun. That volcano we made blew up all over the classroom!" After a thoughtful pause he says, "I guess I want to be friends with Nicholas again, but I don't know how."

"How about if we all sit down after lunch and try to work through this?"

Patrick agree, "Okay, after lunch."

As they walked to the doorway, Patrick turns around and hugs Mrs. Vox and says, "Thanks."

Comparison. In the first scenario, Mrs. Vox did not understand Patrick's perceptions because she did not enter into a dialogue with him. Without the dialogue, Patrick was neither helped to understand his emotions nor taught about the effects his emotions have on behavior. He continued to fume, consumed in anger and certain in his perceptions. He probably did not learn any self-control but instead felt even more justified in his assault on Nicholas. When children's behavior is controlled by someone else and they begin to rely on that, they begin to lose sight of their own responsibility for their actions (Glasser, 1986).

In the second scenario, Mrs. Vox entered the dialogue, in a nonjudgmental way, without a predetermined outcome. She did so only with the desire to understand the situation and help Patrick work through it in a positive way. She could have controlled in the dialogue by telling Patrick that his perception of the situation was wrong, that Nicholas had bumped into him by accident, and that he had to apologize to Nicholas. But Mrs. Vox knew that if she tried to control the dialogue, Patrick probably would "turn off." He would not begin to understand the situation or his emotions but, instead, would persist in his anger and his perception. She also could have admonished him for hitting Nicholas so she could be sure he understood that she did not condone his behavior. She knew, however, that if she was accusatory, he probably would become defensive and again would "turn off." Instead she conveyed her understanding of Patrick's perception and helped him focus on his emotions without condoning his behavior. As stated previously, understanding does not mean agreeing with or condoning. Understanding simply provides a context in which differences can be worked through, crises and frustrations can be handled, and relationships can be built.

In this scenario, Mrs. Vox chose to take an empathetic approach to Patrick's behavior rather than a more controlling stance. She already had established a safe space for children to express their viewpoints. Further, she drew on her knowledge about Patrick-for example, that Nicholas and Patrick previously had a good relationship that could be built upon to resolve the crisis. The incident was transformed from a situation in which Patrick was punished, with time-limited effectiveness, to a 'teachable moment,' in which Patrick was allowed to take responsibility for his own actions. Finally, Mrs. Vox was sensitive to including all voices: Patrick's, Nicholas's, and her own.

\section{Techniques for Establishing Dialogue}

Several methods of establishing dialogue with students have been developed over the years. When implemented in a child-centered classroom within the context of care, these techniques can be effective means of building relationships with students so they are encouraged to take responsibility and in the process improve their self-control. For example, Fritz Redl (1959) and his colleagues developed the technique of life space interviewing as a means for helping children be self-reflective in dealing with their problems and frustrations. This technique uses dialogue with a student to explore situations and events that are the context for the student's frustrations and problems. The adult helps the student focus on emotions and perceptions. This is not done in a leading or controlling way. Instead, the student is asked to explain his or her perceptions of a situation or event, and then the adult helps the student make connections between his or her emotions, actions, and situation outcomes and consequences.

Active listening and the use of I-messages are part of another communication system developed by Gordon (1974). This approach uses dialogue to help teachers and students communicate about problematic situations and events in a nonthreatening way. The focus of active listening and the use of I-messages is understanding. Once the student sees that the teacher is invested in understanding the student's perceptions and is not accusatory or judgmental, the student begins to feel safe in exploring his or her emotions and actions in relation to the situation at hand. The teacher then can help the student move into problem solving about the situation. 
Noddings (1991) described dialogue in caring relationships as "interpersonal reasoning" and identified five of its features.

1. An attitude of care and solicitude. This ensures that dialogue within the relationship will ensue. Both parties within the dialogue feel safe to express perceptions and needs without fear of coercion or manipulation.

2. Flexibility. Outcomes are not planned but, rather, the participants explore multiple possibilities as they arise within the dialogue.

3. Attention. Each participant is committed to listening to and understanding the other party.

4. Effort aimed at cultivating the relationship. Each of the parties works at building the confidence and self-esteem of the other, and a safe context for dialogue is provided.

5. A search for an appropriate response. This is the mutual identification and analysis of a range of possibilities that would address the situation or problem being discussed within the dialogue.

Noddings stressed that interpersonal reasoning is not effective unless it takes place within a caring relationship. She stated, "Schools should become places in which teachers and students live together, talk to each other, reason together, take delight in each other's company" (p. 169).

As with any method or procedure, one's intent and philosophy color its implementation. This is true also of dialogue and communication with students. If your intent is child-centered and focused on helping the student gain self-control and responsibility, dialogue can be a powerful vehicle. If, however, your intent is to control and you are focused on reward and punishment, dialogue becomes a "one-way street," replete with potholes of misunderstandings, defensiveness, and dependency. Teachers have the responsibility to make ethical decisions about their interactions with students. Therefore they have to be reflective about the types of relationships they build with students. Equally important is to analyze the effect on the students of the methods and approaches used to build those relationships.

\section{Cognitive Interventions}

During the past decade, cognitive strategies have become more widely used in classrooms (Harris, Wong, \& Keogy, 1985; Kaplan, 1991). This movement stems from shifts in philosophies. First has been a recognition that people's covert thoughts and feelings can intervene and change the impact of antecedents and consequences of events in classrooms (Braswell \& Bloomquist, 1991; Kaplan, 1991); therefore, just rearranging the rewards and punishers in classrooms will not be entirely effective in changing behaviors. Cognition, feelings, and behaviors interact (Harris, 1982). Attention has to be paid to what is going on inside the student's head. What is vital to interventions is understanding the child's perspective.

There also has been a realization that we as teachers will not always be there to control the activities of each child and that children somehow must learn to monitor, control, and evaluate their own behavior (Kaplan, 1991). Cognitive interventions have been shown to increase generalization and maintenance of behaviors (Kaplan, 1991), as well as redirect the locus of control to within the child (Braswell \& Bloomquist, 1991; Kendall \& Braswell, 1985). This mitigates the need for teachers to be police, and gives children a sense of responsibility for and control over their own behavior. Finally, cognitive behavior management techniques have been verified empirically as being effective in helping students change their behaviors in the classroom and in their daily life outside of school as well (Bornstein \& Quevillon, 1976; Davis \& Boster, 1992; Knaus \& McKeever, 1977; Schleser, Meyers, Cohen, \& Thackwray, 1983; Urbain \& Kendall, 1980).

Several different cognitive approaches now are being taught to students to help them learn about and gain control over their own activities. These include teaching skills in problem solving, controlling anger, self-monitoring, managing stress, cognitive restructuring, self-instructional training, and resolving conflicts. All of these interventions have several things in common.

1. The children rather than external agents, such as the teacher, become the ones in charge of their behaviors; thus, children gain greater self-control and in the process move toward an inner locus of control (Kendall \& Braswell, 1985).

2. With almost all techniques, students are taught a step-bystep procedure to identify and deal with situations in their life.

3. Modeling and learning to attend to and control one's internal talk or private speech are often part of these interventions. Learning these skills has a transformative quality. Once a person realizes how empowering they can be, they become integrated into his or her repertoire of responses to events and they become life-long patterns that enhance and facilitate both outlook and response to life events.

These skills seem to fall into two different areas of selfcontrol:

1. Techniques that help us learn how to deal with events in our lives such as conflict situations or problems that we have to solve. These techniques include problem solving, self-management, self-instruction, and conflict resolution.

2. Techniques that help us learn to control our beliefs or reactions to events that may happen to us. These techniques include cognitive restructuring and stress management skills. 
The brief descriptions that follow illustrate how cognitive techniques can be applied within the context of a classroom built upon a constructivist philosophy. More detailed information about teaching such skills is available in sources listed in the reference list.

Cognitive interventions are conceptually consistent with constructivism. Cognitive interventions acknowledge that people are motivated by the perceptions they construct about what is occurring in their environment. By definition, cognitive interventions work between the student's ears - a place that a teacher cannot have access to without having a solid, trusting, and caring relationship in which sharing perceptions is safe. These interventions rely on a child's assessment of his or her physical and social environments, which has to include many voices to enhance the relevance of the intervention and thus increase the likelihood that the child will adhere to it and people in his or her environments will support it. Finally, cognitive interventions are child-centered and transformative. The child shares his or her perceptions of a difficult situation, with input from others, and is active in identifying how a problem is to be resolved and why it is worth resolving.

\section{Problem Solving}

At every age we encounter situations that we need to learn to manage in our life. Problems arise that do not have easy solutions. These may be as simple as how to get home when we miss the bus or as difficult as how to deal with life-threatening situations. Cognitive behavior management skills can help us deal with these dilemmas.

Problem solving usually is taught as a sequence of skills or thought processes (Kaplan, 1991; Spivack, Platt, \& Shure, 1976). Attention must be paid to the child's developmental level in choosing training techniques and to selecting the sophistication level of the skills taught (Davis \& Boster, 1992), but children as young as 4 years of age can learn these skills (Spivack \& Shure, 1974). First the child must recognize that a problem exists and decide what he or she wants to happen in the situation. Second, the child must be able to generate a number of possible solutions to the problem and then have various systems for selecting the best solution. Students with behavior problems tend to see fewer options and are more likely to engage in rigid thinking in problem situations (Spivack \& Shure, 1974); therefore, this is an important skill to emphasize. Finally, the child must be able to plan a strategy to carry out the solution and then look at the consequences of the actions.

Teaching these techniques to children at different developmental ages has been successful in changing children's approaches to problem situations (Spivack, Platt, \& Shure, 1976), with impulsive children (Kendall \& Braswell, 1985) and with children with attention deficit disorder (Braswell \&
Bloomquist, 1991). Spivack and Shure (1974) indicated that improved problem solving has been shown to lead to improved classroom behavior. The following illustrates Rondell's problem-solving skills.

\begin{abstract}
"What will you do next time you feel like hitting a teammate who makes a mistake during the kickball game?" asks the principal of the fifth-grader who is standing, head down, in front of his desk.

Rondell replies, "Well, I'll think about what happened this time-losing my recesses for two weeksand I'll try to count to 10 and just keep playing the best I can in the game."
\end{abstract}

Self management, including self-assessment, self-monitoring, and self-reinforcement, is another set of techniques that children can be taught to help them keep track of and change their behaviors in the classroom. Although these techniques are used in applied behavior management, the act of teaching students control over the method makes these techniques compatible with constructive classroom management. Teaching students to self-manage their behavior enhances generalization and maintenance of skills (Wood \& Flynn, 1978) and is cost-effective in terms of teacher time in the classroom (Kaplan, 1991). Self-regulation also helps move the child's locus of control from external to internal (Carpenter \& Apter, 1988). Most important, it teaches skills that a person can use throughout life.

Self-assessment is a skill that entails teaching children to observe and record their own behavior and compare their behavior to a predetermined standard. For example, a child is being punished frequently for talking out without raising her hand. The teacher talks with the child to be certain the girl understands why she should not call out in a classroom where the students are trying to concentrate on their math. If the student agrees that she wants to eliminate her bad habit, the teacher teaches her how to keep track of how many times she talks out during a half-hour math period. If the standard then is set at only two talk-outs for the half-hour (no one is perfect all the time!), her goal would be to reduce her talk-outs to that number or below. Next the teacher teaches the child to selfmonitor, using internal dialogue to remind herself to stay on task and raise her hand to ask for help. The student continues to keep track of her talk-outs, and when she reaches her goal, she rewards herself (Alberto \& Troutman, 1995).

Self-instruction involves learning skills that contribute to new behaviors. In this process, external descriptions of the steps in a task or problem, given by a model (e.g., a teacher, or spoken aloud by the student), are incorporated gradually into internal speech. Eventually the child no longer even needs to think about what he or she should do, as it has become automatic (Meichenbaum, 1977). Self-instruction works well for teaching academic skills-for example-long division, as well as the steps for following directions or working through a 
frustrating situation without help from an adult (Alberto \& Troutman, 1995).

Conflict resolution is another problem-solving technique. Strategies used in this approach are effective with conflicts ranging in seriousness from fighting that threatens to erupt in violence to name calling or a tussle over the ball on the playground. To learn to coexist peacefully today, children need skills "to express their needs and wants adequately and to create boundaries for themselves in a responsible manner" (Schrumpf, Crawford, \& Usadel, 1991, p. 1).

Conflict resolution entails a process of communication and problem solving that leads to resolution. It helps turn conflicts into win-win situations for everyone involved. Steps involve gathering information about the conflict and clarifying the situation from each participant's view. Then common interests of the two parties are identified, which helps lead to resolution. Options are created through brainstorming. Finally, options are evaluated and a solution is agreed upon. Sometimes students write out an agreement or a contract and the agreement is sealed with a handshake. This process can be mediated by a neutral party trained in peer mediation skills (Schrumpf, Crawford, \& Usadel, 1991). It also can be done by two students trained in conflict resolution. In the latter situation, students should be empathetic or engage in reflective listening as a neutral party may not be available to interpret or clarify events (Katz \& Lawyer, 1994).

\section{Cognitive Restructuring}

Teaching cognitive restructuring with children means helping them to identify their beliefs about themselves and the world, evaluating those beliefs, and then modifying irrational beliefs. Children learn both rational and irrational beliefs as they grow, learn language, and model and incorporate behaviors and beliefs of significant others into their way of thinking. A belief may be irrational if it has no basis in fact, is illogical, or is harmful to the person (Kaplan, 1991).

One way to teach children to examine their beliefs is to use published belief assessments (Knaus, 1974; Kaplan \& Kent, 1986) or to construct a belief assessment as a way of identifying beliefs that might be supporting maladaptive behavior. Published programs such as DIBs for KIDs (Kaplan, 1991), Ellis's rational emotive techniques (Knaus, 1974; Ellis, 1962), or Roush's (1984) techniques for testing and changing beliefs are programs designed to help children reconstruct or change their belief systems. In all of these programs the situation is identified, including the maladaptive behavior and the feelings associated with the behavior. Then the beliefs that support that behavior are identified and tested to see if they are rational or irrational. Finally, rational beliefs are identified. Then the child can "try out" these new beliefs to see how they might change maladaptive responses in a problem situation. Becom- ing aware of irrational beliefs and thoughts can be a powerful tool for reframing one's response to events in life if it is integrated into one's self-management "bag of tricks."

\section{Stress Management}

Stress impacts everyone-children, adolescents, and adults. Even children who have good problem-solving skills and a positive outlook encounter stress. Chandler (1985) has said that much of the inappropriate behavior we see in classrooms today is the direct result of stressful situations that students encounter. Students can be taught stress management skills to help them cope with the daily stressors in their schools, families, and communities.

When teaching children to manage their stress, the following steps are appropriate:

1. Discuss how to recognize stress symptoms, such as faster heart rate, sweaty palms, clenched fists, knots in the stomach.

2. Talk about different kinds of stress, helping children to understand that some stress is good and some is bad.

3. Explain that running away from stress, although that may be our choice, may not be the best way to deal with it because cumulative stress builds up and affects work, health, and ability to function.

4. Teach different ways to deal with stress and help students identify the kinds of situations in which to use these skills.

Physiological techniques such as exercise, relaxation techniques, and watching one's diet can be modeled and taught to students easily. Developmentally appropriate visualization techniques and progressive relaxation work with students of all ages. Creating a regular exercise program and discussing ways to eat healthily also are important.

Integrating cognitive restructuring and problem-solving skills into students' repertoires is another approach to helping students acquire lifelong stress management skills. In addition, time management and assertiveness training are preventive techniques that can help students manage and prevent or alleviate stressful situations (Kaplan, 1991).

We believe that cognitive interventions are consistent with the assumptions of a constructivist philosophy of learning. The focus of cognitive interventions can be on developing children's skills so they can manage their own activities. These skills are not imposed upon students but, rather, are arrived at through interaction between teachers, students, and other significant persons. Children translate the skills into their own knowledge and behavioral repertoires in their individually unique ways. The focus of this approach is upon helping students understand the importance and the power of their thinking skills when dealing with situations they encounter in school and in life. As children's skills increase, their suc- 
cesses contribute to a cyclical, upward spiral of increasing self-esteem and sense of self-efficacy.

The skills do need to be taught in such a way that students can incorporate them into their repertoire of skills in a way that is meaningful to them, or at a moment in time when the relevance of using the technique is evident. Teaching these skills in the aftermath of critical incidents in children's lives is one way to make sure that students can build on already existing pathways, already established experiences. If critical incidents do not occur readily, then referring to incidents or events in the children's recent past when talking about the methods is effective, as again the child is helped to see the relevance and usefulness of the technique. Teaching the skills in a systematic way with simulations of events not within children's experiences does not allow them to integrate and make sense of the skills. The relationship between teachers and children is especially important when teaching these skills. If a teacher whom a child perceives as strong and caring teaches and models these behaviors and skills, the child is more likely to adopt the modeled skills (Kendall \& Braswell, 1985).

\section{Behavioral Techniques}

As noted earlier, the tradition in which teachers have long been trained is one that relies upon a expert model of knowledge transmission. Knowledge is "discovered" by scientists. This knowledge is used to derive technologies, and these technologies then are bestowed upon teachers in their teacher preparation programs for use in the classroom (Skrtic, 1991). As this conceptualization of learning is increasingly called into question (Poplin, 1988), and as a curriculum of care is being emphasized with increasing vigor (Noddings, 1992), we as educators run the risk of falling prey to another fad and peremptorily discarding all the tools and technologies that classroom teachers have used, and admittedly abused, for years.

Behavioral techniques are increasingly portrayed and interpreted as nefarious instruments of a curriculum of control (Jones \& Jones, 1990). The important word in the previous sentence is instrument. Instruments are wielded by human beings. They do not act of their own accord. Whether technologies are used to pursue goals of a child-centered curriculum or a teacher-directed curriculum relies heavily on the teacher and his or her beliefs of the nature of knowledge, the students' and teacher's roles in the creation or transmission of knowledge, and the teacher's sense of how best to manage a classroom, be it through establishment of rules or through building relationships with individual students individually or as a group.

Behavioral techniques, such as contracting, can be used in ways that are compatible with classrooms in which students and teachers are co-learners, where student empowerment is emphasized, and in which all members of that classroom have a voice in what transpires that is both encouraged and re- spected. What follows is discussion of a behavioral technique, its essential features, and how this method can be employed in ways that are consistent with student choice, focus on the child in a holistic manner, and employ child-centered curricula and other key assumptions of the emerging paradigm of educational practice.

\section{Contingency Contracting}

Behavioral techniques often are criticized because behavioral changes are attempted through the imposition of external controls (Jones \& Jones, 1990). When implemented properly, contingency contracting builds students' skills at managing their own behavior by giving the student control through collaborative arrangement with the teacher and other significant persons. Contracting is based on the Premack principle (Premack, 1959), which holds that any behavior that is likely to happen at a given time can be used to strengthen a behavior that has a lesser chance of happening at that time. This idea was incorporated by Homme (1972) when he developed contingency contracting. What frequently is overlooked in employing this method is that contract implies two or more parties on equal footing - that all parties understand the need for an agreement and are aware of the consequences of living up to, or failing to live up to, an agreement. Any contract that does not meet any one of these three conditions is doomed to failure.

Contracts can be used alone or in conjunction with other techniques such as self-monitoring. The consequences of contracts might involve token, social, or activity reinforcers. Every effort should be made to begin as simply as possible and use naturally occurring consequences if possible.

Contracting has been criticized for focusing on controlling misbehavior. Although this is not a misuse of the technique, contracts often are overlooked for the help they can provide in promoting prosocial behaviors. Rewarding positive behaviors will assist in building self-esteem when this is an issue.

Further, contracting does not have to be limited to classroom behaviors. It can be an excellent vehicle for strengthening bonds with the family or caregivers. To foster collaborative relationships between teachers and caregivers, caregivers should have more of a role than simply signing a note at the end of the school day. Creative uses of contracting can provide consistency across all spheres that make up a child's world, and caregivers have unique insights into the types of behaviors they are most interested in changing and into the types of consequences that are most relevant to the child.

Contingency contracts can be developed for individuals and groups, depending on the nature of the target behavior. Group contracting gives children a sense of being in charge of their classroom and of themselves and can facilitate important social skills such as problem solving and negotiation. For example, group contracts can be made a part of a civics lesson on how people get along in society, how and why laws are made, 
and what happens when laws are not obeyed.

The following, adapted from Epanchin, Townsend, and Stoddard (1994) outlines some steps as a guide in developing contingency contracts.

1. The teacher and the student explore the reason(s) and rationale(s) for targeting a given behavior and agree upon the importance of selecting that behavior.

2. The parties to the contract negotiate a precise definition of the behavior and the circumstances under which it is to occur.

3. The parties discuss the consequences of living up to or failing to live up to the contract until reaching mutual satisfaction.

4. The parties draw up a contract outlining the behavior of interest and the contingencies.

5. All parties sign the contract.

Contracts have many positive features. They enable teachers to build on children's strengths rather than focus solely on their shortcomings. They provide a way to individualize the learning situation so children can be successful. Teachers also are able to enlist the assistance, advice, and support of other people who are important in children's lives. Contracts are used most effectively by teachers who trust themselves and others to relinquish their need to control every event and person in their classroom. Teachers who are skilled in using dialogue as a means of developing solid, caring relationships with their students are able to establish a safe context for learning. The important lesson about contracting, as well as other behavioral techniques, is to base the contract on knowledge of the child and to have an open and creative mind in developing the contract.

\section{Point and Level Systems}

Point and level systems, although derived from behavioral assumptions, also can be used within a constructivist classroom as long as the teacher maintains a child-centered focus and incorporates strategies that give the student a voice in determining outcomes. Behavioral techniques are consistent with constructivist principles when students have responsibility for design and implementation of the plan. If feedback about progress toward intended goals and choice among alternatives occurs at each stage of implementation, teachers ensure that the student's voice and needs are addressed.

When using these techniques, teachers need to feel comfortable functioning in the role of helping children learn to control themselves rather than their traditional role of enforcing rules and consequences (Bauer \& Sapona, 1991; Epanchin, 1982). Choices should not apply solely to selection of the rewards, incentives, and reinforcement schedules. To increase relevance, and thereby increase likelihood of success within and generalization across settings, the children should identify specific behaviors they think will require some work and the order and manner in which to address them.

Point and level systems should not be viewed as cookie cutter interventions with universal application for all children. The first question always should be to ask whether this child will benefit from the system. If so, the design should account for the child's individual circumstances and his or her developmental needs. If instituted in the spirit of collaboration, these systems can provide one more way in which children can be in charge of their own behavior rather than rely on external controls.

\section{CONCLUSIONS}

We realize that the strategies presented in this article are not new ones, but they are ones that enable teachers to create safe, caring environments in which students are the focus. They are strategies that enable teachers to learn about their students, to teach them content that is relevant and meaningful, and to support and help students' efforts to grow and develop. The techniques, however, are only as effective as the teacher using them. Child-centered, constructivist classroom management is not dependent upon these strategies. Rather, it depends upon the teacher's philosophy and outlook. Teachers who respect and care about their students and who believe their job is to enable and facilitate growth and development, not direct and judge children's behavior, can use these techniques effectively. Teachers who are comfortable judging what is best for children and how families and children should behave are not likely to use these techniques effectively. At the heart of a constructivist classroom is a nonjudgmental way of thinking that puts understanding and empathizing with children at the center. Through a caring relationship embedded in a constructivist philosophy of learning, we believe teachers can give their students lifelong skills for getting along in school, in work, and in interpersonal relationships.

\section{REFERENCES}

Alberto, P., \& Troutman, A. C. (1995). Applied behavior analysis for teachers (3d ed.). New York: Merrill Publishing.

Aspy, D. N., \& Buhler, J. H. (1975). The effect of teachers' inferred self-concept upon student achievement. Journal of Educational Research, 68, 386-389.

Barth, R. (1986). Social and cognitive treatment of children. San Francisco: Jossey-Bass.

Bauer, A. M., \& Sapona, R. H. (1991). Managing classrooms to facilitate learning. Englewood Cliffs, NJ: Prentice Hall.

Bornstein, P., \& Quevillon, R. (1976). The effects of a self-instructional package on overactive preschool boys. Journal of Applied Behavior Analysis, 9, 179-188.

Braswell, L., \& Bloomquist, M. (1991). Cognitive behavioral therapy with ADHD children: Child, family, and school interventions. 


\section{FOCUSO Exceptional children}

New York: Guilford Press.

Bruner, J. (1986). Actual minds, possible worlds. Cambridge, MA: Harvard University Press.

Carpenter, R., \& Apter, S. (1988). Research integration of cognitiveemotional interventions for behavior disordered children and youth. In M. C. Wang, M. C. Reynolds, \& J. Walberg (Eds.), Handbook of special education: Research and practice, (Vol. 2). New York: Pergamon Press.

Chandler, L. (1985). Assessing stress in children. New York: Praeger Press.

Davis, D., \& Boster, L. (1992). Cognitive behavioral-expressive interventions with aggressive and resistant youths. Child Welfare, 71(6), 557-573.

Eitzen, D. (1992). Problem students: The sociocultural roots. Phi Delta Kappan, 73, 584-590.

Ellis, A. (1962). Reason and emotion in psychotherapy. New York: Lyle Stuart Press.

Epanchin, B. C. (1982). Behavior management. In J. L. Paul \& B.C. Epanchin (Eds.), Emotional disturbance in children. Columbus, $\mathrm{OH}$ : Merrill Publishing.

Epanchin, B. C., Townsend, B., \& Stoddard, K. (1994). Constructive classroom management: Strategies for creating positive learning environments. Pacific Grove, CA: Brooks-Cole Publishing.

Glasser, W. (1986). Control theory in the classroom. New York: Harper \& Row

Goodlad, J. (1984). A place called school: Prospects for the future. New York: McGraw Hill.

Gordon, T. (1974). Teacher effectiveness training. New York: McKay.

Harris, K. R. (1982). Cognitive-behavior modification: Applications with exceptional students. Focus on Exceptional Children, 15(2), $1-16$.

Harris, K. R., Wong, B. Y. L., \& Keogy, B. K. (Eds.) (1985). Cognitive-behavior modification with children: A critical review of the state of the art. Journal of Abnormal Child Psychology, 13(3), $329-476$.

Homme, L. (1972). How to use contingency contracting in the classroom, (Rev. Ed.). Champaign, IL: Research Press.

Johanningmeier, E. V. (February, 1993). An exploration of learning: Some notes on an inquiry into how E. L. Thorndike approached learning: Some observations on the consequences and some recommendations. Paper presented at annual Southeast Philosophy of Education Society, Auburn University, Auburn, AL.

Jones, V. F., \& Jones, L. S. (1990). Comprehensive classroom management: Motivating and managing students. Boston: Allyn \& Bacon.

Kaplan, J. (1991). Beyond behavior modification: A cognitive behavioral approach to behavior management in the school. Austin, TX: Pro-Ed.

Kaplan, J., \& Kent, S. (1986). PRE-COD II: A computer-assisted program in behavioral analysis. Austin, TX: Pro-Ed.

Katz, N., \& Lawyer, J. (1994). Preventing and managing conflict in schools. CA: Corwin Press.

Kendall, P., \& Braswell, L. (1985). Cognitive-behavioral therapy for impulsive children. New York: Guilford Press.

Knaus, W. (1974). Rational-emotive education: A manual for elementary school teachers. New York: Institute for Rational Living.

Knaus, W., \& McKeever, C. (1977). Rational emotive education with learning disabled children. Journal of Learning Disabilities, 10, $10-14$.
Knitzer, J., Steinberg, A., \& Fleisch, B. (1990). At the schoolhouse door: An examination of programs and policies for children with behavioral and emotional problems. New York: Bank Street College of Education.

Kozol, J. (1991). Savage inequalities: Children in America's schools. New York: Holt, Rinehart \& Winston.

Kreisberg, S. (1992). Transforming power: Domination, empowerment, and education. Albany: State University of New York Press.

Meichenbaum, D. (1977). Cognitive behavior modification: An integrative approach. New York: Plenum Press.

Nichols, P. (1992). The curriculum of control: Twelve reasons for it, some arguments against it. Beyond Behavior, 3, 5-11.

Noddings, N. (1991). Stories in dialogue: Caring and interpersonal reasoning. In C. Witherell \& N. Noddings (Eds.), Stories lives tell: Narrative and dialogue in education, pp. 157-171. New York: Teacher's College Press.

Noddings, N. (1992). The challenge to care in schools: An alternative approach to education. New York: Teachers College Press.

Piaget, J. (1986). The construction of reality in the child. New York: International Universities Press.

Poplin, M. (1988). Holistic/constructivist principles of the teaching/ learning process: Implications for the field of learning disabilities. Journal of Learning Disabilities, 7, 401-415.

Poplin, M., \& Weeres, J. (1992). Voices for the inside: A report on schooling from inside the classroom. Claremont, CA: Institute for Education in Transformation.

Premack, D. (1959). Toward empirical behavior laws: Positive reinforcement. Psychological Review, 66, 219-233.

Raffini, J. (1993). Winners without losers. Boston: Allyn \& Bacon.

Redl, F. (1959). The life space interview in the school setting. American Journal of Orthopsychiatry, 33, 717-719.

Roush, D. (1984). Rational-emotive therapy and youth: Some new techniques for counselors. Personnel \& Guidance Journal, 62, 414-417.

Schlechty, P. (1990). Schools for the 21st century: Leadership imperatives for educational reform. San Francisco: Jossey-Bass.

Schleser, R., Meyers, A., Cohen, R., \& Thackwray, D. (1983). Selfinstruction interventions with non-self-controlled children: Effects of discovery versus faded rehearsal. Journal of Consulting \& Clinical Psychology, 51, 954-955.

Schrumpf, F., Crawford, D., \& Usadel, H. (1991). Peer mediation: Conflict resolution in schools. Champaign, IL: Research Press.

Skrtic, T. M. (1991). Behind special education: A critical analysis of professional culture and school organization. Denver: Love Publishing.

Spivack, G., Platt, J., \& Shure, M. (1976). The problem solving approach to adjustment. San Francisco: Jossey-Bass.

Spivack, G., \& Shure, M. (1974). Social adjustment of young children: A cognitive approach to solving real-life problems. San Francisco: Jossey-Bass.

Urbain, E., \& Kendall, P. (1980). Review of social-cognitive problem-solving interventions with children. Psychological Bulletin, 88, 109-143.

Wood, R., \& Flynn, J. (1978). A self-evaluation token system vs. an external token system alone in a residential setting with predelinquent youth. Journal of Applied Behavior Analysis, 11, 503-512. 